Hughes, W. H. (1955). J. gen. Microbiol. 12, 269-274

\title{
The Differences in Antibiotic Sensitivity of Closely Related Single Cells of Proteus vulgaris
}

\author{
BY W. HOWARD HUGHES \\ Wright-Fleming Institute of Microbiology, St Mary's Hospital Medical \\ School, London, W. 2
}

SUMMARY: Evidence is offered that when a single bacterial cell divides the daughter cells are frequently unlike one another. This can be demonstrated by separating cells, allowing them to divide and then transferring individuals derived from them to agar containing a suitable concentration of antibiotic. Differences between single cells can be tested by four criteria: (1) division; (2) growth without division; (3) ability to resume division when transferred back to normal broth; (4) failure to lyse.

Previous results on the distribution of antibiotic sensitivity in cultures from single cells show that a wide range of differences is present (Hughes, 1952; Eagle, Fleischmann \& Levy, 1952). This would be explained if either mutation were very frequent or if changes appeared at each division giving two daughter cells which might differ appreciably from each other. Evidence that two cells with different characteristics could arise from the division of a single parent cell has already been presented (Hughes, 1953 $a$ ). Then it was shown that under anaerobic conditions on nutrient agar single cells of coliform organisms divided to give one cell which was normal and established a colony, and one cell which was unable to divide and gave rise to a long form.

It had also been noticed that when a culture of Proteus vulgaris grown from a single cell was exposed to penicillin, the appearances of the cells differed according to the concentration of the antibiotic (Hughes, 1953b). Also, at any one concentration the effect on the individual cells differed so that some were able to multiply while others were unable to divide or were lysed (Table 1). One typical field from such a culture is shown in Pl. 1, fig. 1. Of three organisms all derived from a $3 \mathrm{hr}$. subculture one is undergoing autolysis, one has grown but is unable to divide, while one has already divided into four, of which three are showing early swellings while the fourth, though large, shows no definite abnormality.

A method for examining individual cells of Proteus vulgaris for resistance or susceptibility based on this type of observation was elaborated.

\section{METHODS}

The experiments were carried out in the oil-chamber of a de Fonbrune micromanipulator and observed by phase-contrast microscopy.

A batch of Hartley's digest broth was prepared, filtered to free it from any dead organisms, measured into bottles and used throughout the experiments. From the same batch of broth $2 \%$ nutrient agar was also prepared 
Table 1. Effect of variation of concentration of pencillin on the morphology and viability of individual cells of Proteus vulgaris

\begin{tabular}{lrrrrr} 
& \multicolumn{5}{c}{ Concentration of penicillin in units $/ \mathrm{ml}}$. \\
\cline { 2 - 6 }$\quad$ Morphology of cells & 0 & 2 & 3 & 4 & 5 \\
Normal & 93 & 55 & 20 & 0 & 0 \\
Abnormal dividing & 6 & 30 & 76 & 36 & 17 \\
Abnormal not dividing & 0 & 12 & 4 & 46 & 77 \\
Lysed & 0 & 0 & 0 & 18 & 6
\end{tabular}

and dispensed into screw-capped bottles each containing $\mathbf{2} \cdot \mathbf{0} \mathrm{ml}$. For use one bottle of agar was melted and an equal volume of penicillin dissolved in broth added to give the required final concentration in $1 \%$ agar. A large drop of the penicillin agar was then poured on to a sterile slide and allowed to set. A number of blocks $1 \times 1.5 \mathrm{~mm}$. in size were cut from this and arranged on
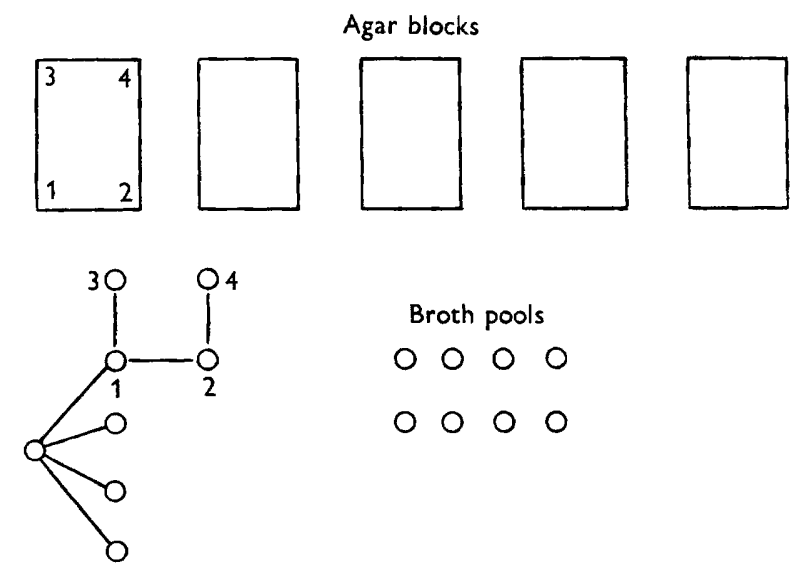

Fig. 1. Suitable arrangement for the study of the sensitivity of single cells to antibiotics.

the coverslip, together with a pool of sterile broth and a separate drop of a $3 \mathrm{hr}$. culture of the stock organisms in broth. The coverslip was inverted and the chamber filled with oil. Next, a pattern of drops of broth was made with the micropipette, arranged as shown in Fig. 1.

A single cell was taken into the first drop and incubated either at room temperature or at $37^{\circ}$ until it had divided into four or more. Each of these cells was placed in a separate drop and allowed to divide to give 4 or more cells which were again separated. At this stage differences in growth rates were apparent and during the time that one of the small cultures took to become four cells others had reached totals of up to sixteen. Each of these small groups was allotted an agar block containing penicillin and each cell was placed at a marked position on it so that it could be identified, observed and rescued at the appropriate time. 
Since it might have been thought possible that organisms could influence one another genetically or otherwise by sharing a block, the experiment was reduced in scale and the patterns modified by providing a separate block of agar for each cell. When this was done no differences were detected and it appeared to be an unnecessary complication.

The preparation was now incubated at $37^{\circ}$ for $2 \mathrm{hr}$. when the blocks contained $10 \mathrm{u}$. penicillin $/ \mathrm{ml}$, , or overnight when lower concentrations were used. With other strains the concentration and time would be different. Four tests can now be applied to the individual cell; (1) division; (2) growth without division; (3) ability to resume growth when returned to normal broth; (4) failure to lyse. Using these criteria the sensitivity of individual cells was examined.

After incubation the cells, whether apparently affected by the exposure to penicillin or not, were transferred to drops of normal broth and the preparation reincubated. Cells which did not divide were assumed to be dead or dying. A few of them, though obviously motile, were dying, for division was not resumed; it was found that these all lysed within $48 \mathrm{hr}$., like all those which failed to divide. Since the large forms produced on penicillin consist of more than one cellular unit, it is possible for part to be dead and the remainder living; such an organism was classed as living but its occurrence emphasizes that differences are present before division has taken place.

\section{RESULTS}

Even without penicillin being present, a small number of cells from most strains will be adversely affected. Controls with nutrient agar free of penicillin were examined. These showed up to $1 \%$ of long forms which were unable to divide.

A typical experiment using $10 \mathrm{u}$. penicillin $/ \mathrm{ml}$. in the agar is shown in Fig. 2. The microculture consisted of a clone of sixteen cells, of which nine were taken to establish small groups and details of these are given; it was impossible in the time to handle the remainder. Cell 1 appears the most sensitive, only one daughter cell was able to grow at all, none divided and all four were dead within 2 hr. Cell 3 gave the most highly resistant group with three viable cells, all cells survived for some time, grew into long forms and three divided or completed division. Cell 5 was intermediate between the other two and was representative of the remaining six groups. It may be significant that of the six viable cells demonstrated by transferring to normal broth, three were in a single group.

Fig. 3 gives the results of overnight cultures of eight microcolonies on weaker penicillin. Here one cell was taken and allowed to develop into eight which were isolated from each other and allowed to continue growing to give the eight related groups. Differences in growth rates were now apparent, the numbers of cells produced in the same time ranging from three to eight. These were explanted on $7 \cdot 5 \mathrm{u} . / \mathrm{ml}$. penicillin agar. At this concentration with this preparation long swollen forms were not produced and the cells either lysed or formed small colonies during the night. 


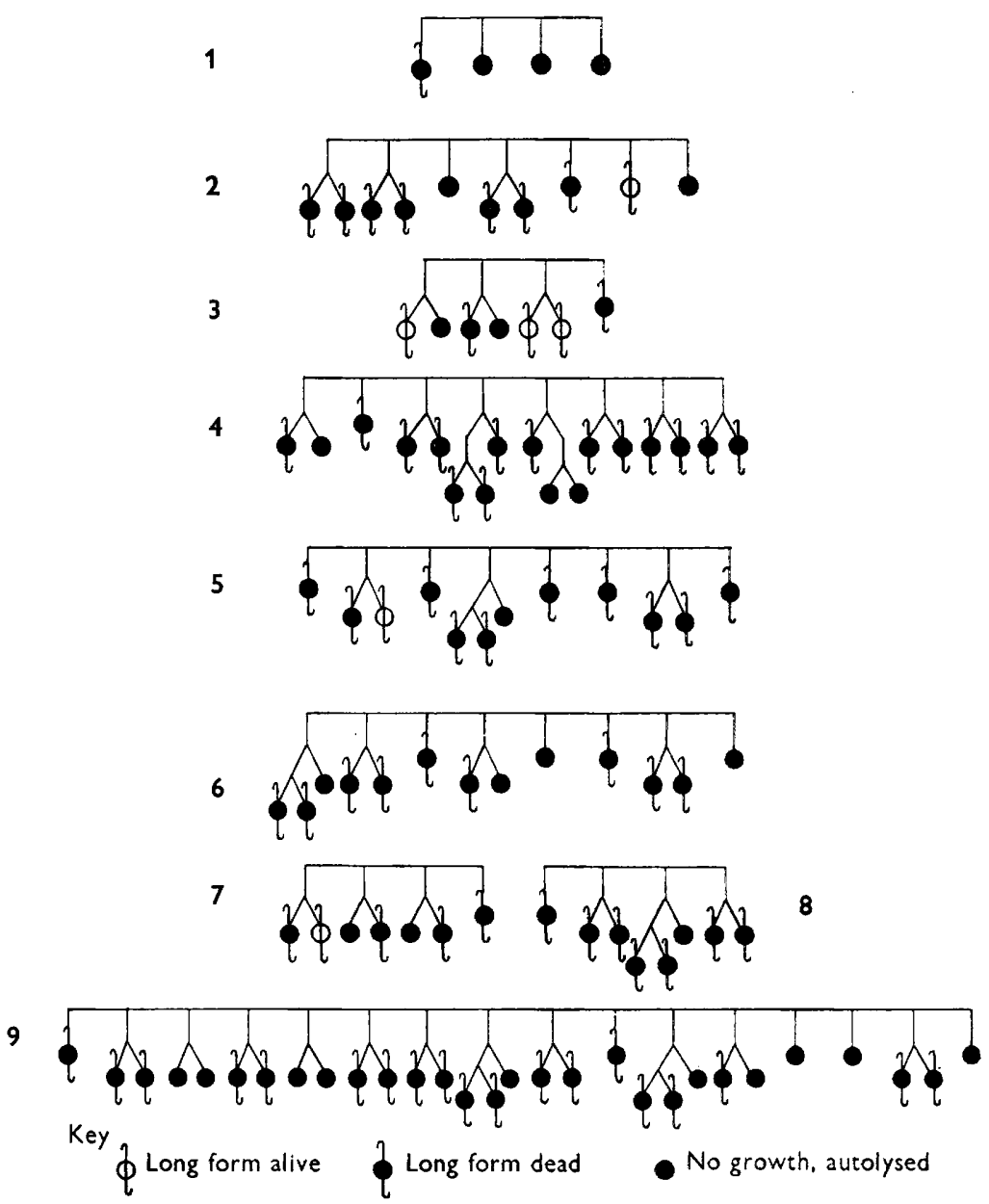

Fig. 2. The effect of $10 \mathrm{u}$. penicillin $/ \mathrm{ml}$. on the individual cells of nine microcultures, grown from nine members of a clone of sixteen cells.
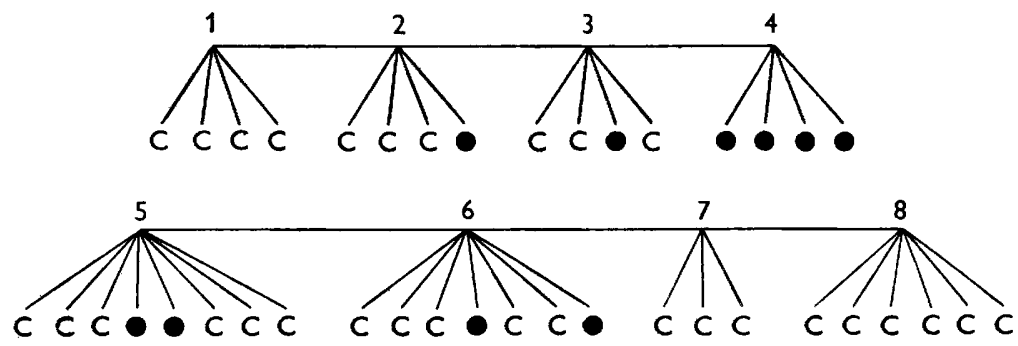

- Organism died C Organism formed colony

Fig. 3. Diagram showing fate of eight microcolonies derived from the same single cell when plated out on $7 \cdot 5 \mathrm{u}$. penicillin/ml. agar. 
Here, as in the last experiment, sensitivity is not distributed evenly throughout the groups; for instance, the whole of group 4 lysed.

Although this work was done with penicillin and Proteus vulgaris, experiments were also made with coliforms, and with other antibiotics such as streptomycin and terramycin, which gave similar results.

\section{DISCUSSION}

The type of variation illustrated by these experiments has been little studied. There is no reason to suppose that transformation, transduction or any form of genetic recombination is taking place. If we regard the varying sensitivity of closely related cells as due to mutations, we must allow a very high rate of mutation, of the order of one in two divisions. The fact that the more closely related the cells are the more likely they are to share either sensitivity or resistance suggests that these characteristics are determined before contact with the antibiotic though they can only be detected in its presence. It may be necessary to test at each division, rather than allowing small groups to develop, in order to establish this. One explanation would be that before each division the factors determining hereditary characters, whether equivalent to the genes of higher plants or not, are redistributed in such a way that their spatial relationship is altered. During such a process nothing would be lost by the cells; no permanent changes would take place so that if the more sensitive cells were rescued from the adverse influences in time the cultures derived from them would contain similar elements to the parent strain, though the proportion of sensitive and resistant cells would have altered. Were the loss of a hereditary element responsible for either sensitivity or resistance, then the sensitive or resistant cell would produce only progeny of the same type, unless there were introduction of fresh genetic material; these experiments were designed to avoid any possibility of the latter.

To keep these strains constant a selection pressure must be maintained for a considerable time. It has proved possible by selection of single cells from cultures exposed to $5 \mathrm{u}$. penicillin/ml. as in experiments described previously, choosing those that were most normal in appearance, subculturing from these and repeating the process, to increase the average resistance of a culture, but after twenty-six such subcultures an increase in tolerance from 5 to $10 \mathrm{u}$. penicillin/ml. was all that had been obtained.

In previous work in which resistant strains have been bred out from populations, no evidence was available of the frequency with which more sensitive cells appeared in the cultures, since most methods used were designed to kill off all but the most resistant variants. Rowley (1952) has shown that sensitive mutants appear in irradiated cultures but he was dealing with induced mutattions. The 'family tree' type of experiment used here establishes that there are differences between sister cells. Cooper at the April 1954 meeting of the Society for General Microbiology suggested that the stage of growth at the time of exposure may be the determining factor in a cell's survival. Growth rates, even of members of a microcolony, are certainly different and the 
individual cells will be at different stages when planted out. Nevertheless, some of them divide on the penicillin agar and then it will be impossible for the daughter cells to be in different stages of growth, yet one may survive while the other dies. Unequal distribution of hypothetical cytoplasmic elements between the two cannot be entirely excluded.

\section{REFERENCES}

Eagle, H., Fleischmann, R. \& Levy, M. (1952). Development of increased bacterial resistance to antibiotics. $J$. Bact. 63, 623 .

Hughes, W. H. (1952). Variation in penicillin resistance in single-cell cultures of Staphylococcus aureus. J. gen. Microbiol. 6, 175.

Hughes, W. H. $(1953 a)$. The origin of the L-form variants in anaerobic cultures of Bacterium coli. J. gen. Microbiol. 8, 307.

Hughes, W. H. (1953b). In Adaptation in Micro-organisms. Symp. Soc. gen. Microbiol. 3, 250.

Rowley, D. (1952). Selection of penicillin-sensitive mutants of Escherichia coli following ultra-violet irradiation. J. gen. Microbiol. 6, 272.

\section{EXPLANATION OF PLATE}

Fig. 1. Variation in effect of penicillin on cells of Proteus vulgaris derived from the same single cell.

(Received 11 October 1954) 
Journal of General Microbiology, Vol. 12, No. 2

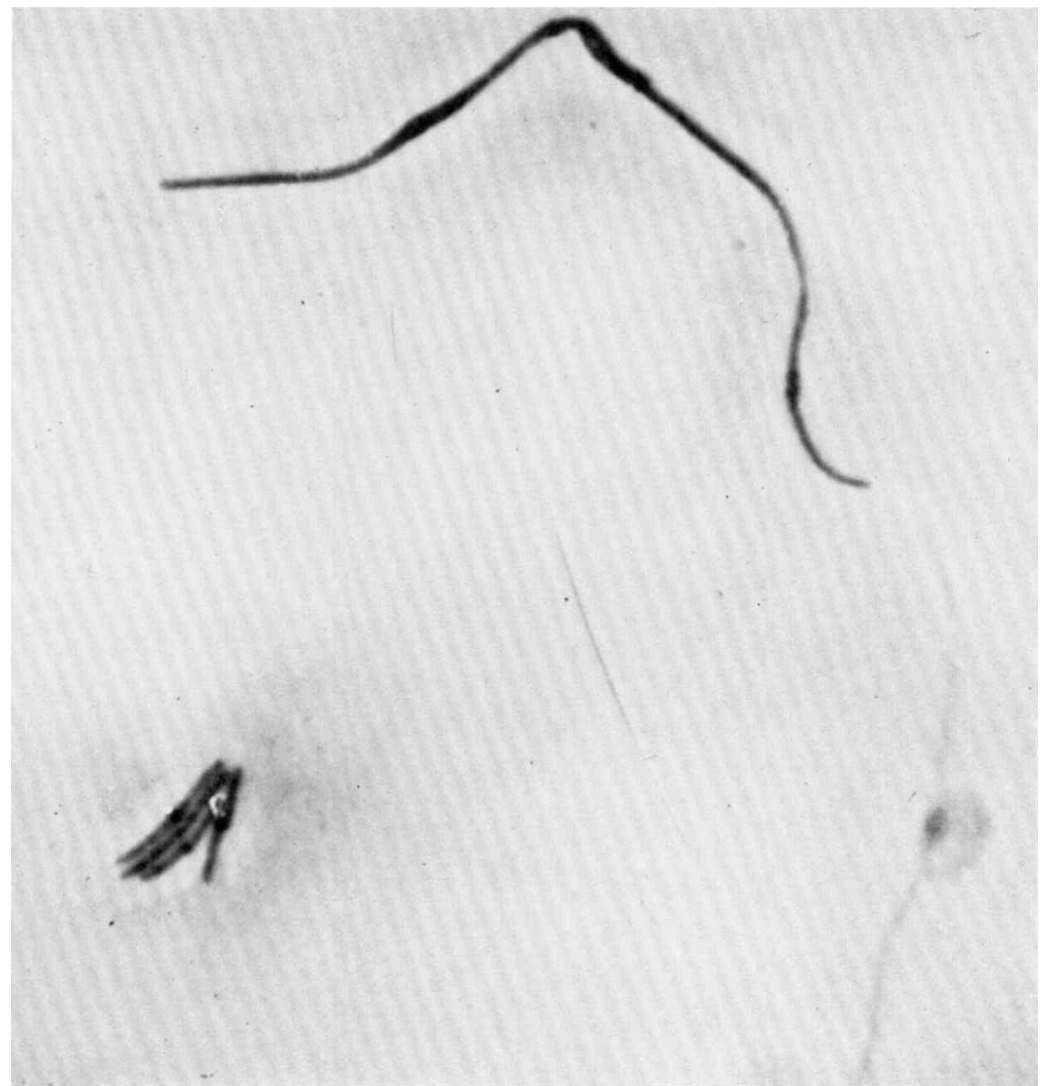

W. Howard Hughes-Differences in related single cells. Plate 1 